\title{
Supplementation of Powdered Black Cumin (Nigella sativa) Seeds Reduces the Risk of Hypercholesterolemia
}

\author{
M. Tauseef Sultan', Masood Sadiq Butt ${ }^{2}$, Rabia Shabeer Ahmad ${ }^{3}$, Rizwana Batool' \\ Ambreen $\mathrm{Naz}^{2}$, Hafiz Ansar Rasul Suleria ${ }^{2}$
}

${ }^{1}$ Department of Food Sciences, Bahauddin Z akariya University Multan, Pakistan; ${ }^{2}$ National Institute of Food Science and Technology, University of Agriculture, Faisalabad, Pakistan; ${ }^{3}$ Department of Food Sciences, GC University, Faisalabad, Pakistan

Corresponding author: M. Tauseef Sultan PhD, Department of Food Sciences, Bahauddin Zakariya University, Multan, Pakistan

Submission date: October 31, 2011; Acceptance date: December 13, 2011; Publication date: December 30, 2011

\begin{abstract}
:
Background: Functional and nutraceutical foods are gaining immense popularity among the masses. Plants and their bioactive molecules are of prime importance. Although various plants from different geographical areas have been tested in the past, many horizons still need to be addressed. Black cumin (Nigella sativa L.) is one such example that is quite popular in South Asia and the Middle East.
\end{abstract}

Context and purpose: The present research study was designed to expedite the role of black cumin seed in reducing the risk of hypercholesterolemia. For the purpose, thirty Sprague dawley rats were procured from the National Institute of Health (NIH) in Islamabad, Pakistan, and further split up into three groups, (10 rats each). Experimental diets were prepared using powdered black cumin (PBC) at $1 \%$ and $2 \%$, and compared with the placebo.

Results: The results revealed that PBC was effective in reducing the serum cholesterol, triglycerides, and low-density lipoproteins (LDL). Additionally, the experimental diets resulted in a non-significant increase in high-density lipoprotein (HDL). Overall, powdered black cumin at $1 \%$ and $2 \%$ reduced cholesterol level by 6.73 , and $4.48 \%$, LDL by 24.79 , and $24.32 \%$ respectively. However, the supplementation of $\mathrm{PBC}$ at $2 \%$ resulted in marked variations as increasing tendency, which was recorded for cholesterol and triglycerides contents after 28 days of study.

Conclusion: Present research investigation brightened the prospects of using powdered black cumin seed in diet based therapies to improve the lipid profile. Further studies are still required to assess the phytochemistry of the plants and indeed the functional ingredients responsible for such health benefits. Such studies would bring meticulousness for utilization of black cumin seeds as a functional food.

Keywords: Functional foods, black cumin, lipid profile, cholesterol, triglycerides 


\section{BACKGROUND:}

The diet-health linkage is a prime area of research in the domain of nutrition. The concepts of functional and nutraceutical foods flourished as a results of such research interventions. The consumer trends have also widened, and many have begun to look at food not only for its basic nutrition, but also for the allied health benefits [1-2]. Therefore, opportunities abound in functional foods to combat oxidative stress, hyperglycemia, and hypercholesterolemia. Now it's the responsibility of the nutritionists to pay attention towards their health claims and their safety issues [3-4].

Black cumin (Nigella sativa L.) contains several bioactive molecules that include thymoquinone, thymol, tocopherols, tocopherol, trans-retinols, and selenium. These functional ingredients are predominantly present in its fixed and essential oil [5]. N. sativa seeds also contain proteins, alkaloids (nigellicines and nigelledine), and saponins ( $\alpha$-hederin) in substantial amounts. Black cumin seeds have been used as herbal medicine by various cultures and civilizations to treat and prevent the number of diseases to ensure good health. Recent pharmacological investigations suggested its potential role, specifically for the amelioration of oxidative stress through free radical scavenging activity, the induction of apoptosis to cure various cancer lines, the reduction of blood glucose, and the prevention of complications from diabetes. It regulates hematological and serological aspects and can be effective in dyslipidemia and respiratory disorders. Moreover, its immunopotentiating and immunomodulating role brings balance to the immune system. Evidence is available supporting the utilization of Nigella sativa and its bioactive components in a daily diet for health improvement [6]. Like most herbs, the composition of black cumin varies with geographic distribution, time of harvest, and agronomic practices [7]. Black cumin seeds contain appreciable quantities of unsaturated especially polyunsaturated fatty acids (48 to $70 \%$ ), while monounsaturated (18 to $29 \%$ ), and saturated fatty acids (12 to $25 \%$ ), are in lesser proportions. Besides a better fatty acid profile, it contains considerable quantities of tocopherols and allied bioactive compounds. Moreover, the presence of phytosterols in amounts of 0.33 to $0.36 \%$ further strengthens its hypoglycemic and hypoholesterolemic perspectives [8]. Several pharmacological investigations explored the effectiveness of thymoquinone against oxidative stress, cancer, immune dysfunction, and diabetic complications. Furthermore, it also regulates several hematological and serological functions, it maintains body homeostasis and bears a hypocholesterolemic effect [9].

Black cumin is a promising candidate in dietary modifications and could be utilized directly in the daily diet, or added as a functional ingredient in cereal based products [10]. Keeping in view the above information, the present research project was designed to expedite the role of black cumin (Nigella sativa L.) seed in reducing the risk of hypercholesterolemia. For the purpose, powdered black cumin seeds at $1 \%$ and $2 \%$ were added in the experimental diets of rodents and their influence was observed in balancing the lipid profile.

\section{METHODS:}

Black cumin seeds of the indigenous variety were obtained from Barani Agricultural Research Institute (BARI), Chakwal. Materials for experimental diets were procured from local markets, while the chemical and kits were purchased from Merck (Merck KGaA, Darmstadt, Germany). 
Proximate and nutritional composition: The black cumin seeds were ground to 50mm mesh size, and further evaluated for their proximate composition as described in AACC [11]. The fixed and essential oils were also analyzed and the results are already published (See: Sultan et al. [5] Published in Pakistan Journal of Botany).

Efficacy study \& housing of rats: In order to explore the hypocholesterolemic perspectives, experimental diets containing $1 \%$ and $2 \%$ powdered black cumin seeds were prepared, and the rest of the formulation remained the same as suggested by the National Institute of Health (NIH). Sprague dawley rats were maintained according to standard guidelines: they were housed in groups of ten in stainless steel top grill cages, with a controlled temperature $\left(23 \pm 2^{\circ} \mathrm{C}\right)$, a relative humidity (55 $\pm 5 \%$ ), and a 12 hour light-dark cycle. Food and water was provided ad libitum, and their intake was monitored on a daily basis. Half of the overnight fasted rats were sacrificed after four weeks of the feeding trail, and the rest were sacrificed at the end of study. Blood samples were collected through cardiac puncture, and serum was collected following the method of Uchida et al. [12].

Serum lipid profile: The lipid profile includes cholesterol, high-density lipoprotein (LDL), lowdensity lipoprotein (LDL), and triglycerides. For the purpose, cholesterol in the collected serum of individual rats of all groups was measured by the liquid cholesterol CHOD-PAP method, as described by Stockbridge et al. [13], to find out the effect of the individual diet on the cholesterol level of respective groups. Serum High Density Lipoprotein (HDL) was measured by the HDL Cholesterol Precipitant method as described by Assmann [14]. Low Density Lipoprotein (LDL) was measured by following the procedure of McNamara et al. [15]. Triglycerides in the collected serum of individual rats were measured by liquid triglycerides GPO - PAP method, as described by Annoni et al. [16].

Statistical analysis: Data obtained was analyzed statistically using the statistical package i.e. Cohort V-6.1 (Co-Stat-2003). The sample for each analysis was run quadruplet, and the values expressed are means \pm the standard deviation. Analysis of variance was applied to check the level of significance, and the means were compared through Tukey's HSD tests.

\section{RESULTS:}

Diet based therapies are gaining immense importance and usually rely on plant based remedies. Black cumin (Nigella sativa) is quite famous in Muslim communities. In the present research investigation, the efforts were diverted to utilize powdered black cumin seeds at $1 \%$ and $2 \%$ in the diets of Sprague dawley rats to assess the efficacy of black cumin as hypoglycemic agent.

The results obtained were subjected to statistical analysis using two factor-factorial design and mean squares (Table 1), which explicated that the lipid profile was affected significantly as a function of diets, except for high-density lipoprotein (HDL), while study intervals and their interaction remained non-significant with exception of their momentous impact on low-density lipoprotein (LDL). 
Table 1. Effect of diets and study intervals on serum lipid profile in normal rats

\begin{tabular}{llllll}
\hline SOV & Df & Cholesterol & HDL & LDL & Triglycerides \\
\hline Diets (A) & $\mathbf{2}$ & $0.4743 \mathrm{~ns}$ & $2.0657 \mathrm{~ns}$ & $2.5846^{*}$ & $4.1410^{*}$ \\
Intervals (B) & $\mathbf{2}$ & $2.5608 \mathrm{~ns}$ & $1.4493 \mathrm{~ns}$ & $0.3864 \mathrm{~ns}$ & $13.2879 * *$ \\
A x B & $\mathbf{4}$ & $0.8087 \mathrm{~ns}$ & $0.3138 \mathrm{~ns}$ & $1.2035 \mathrm{~ns}$ & $3.3782^{*}$ \\
Error & $\mathbf{3 6}$ & 0.4743 & 2.0657 & 2.5846 & 4.1410 \\
Total & $\mathbf{4 4}$ & & & & \\
\hline
\end{tabular}

ns $=$ Non-significant $; *$ Significant $* * *=$ Highly significant

Diets containing powdered black cumin seeds reduced cholesterol contents significantly as compared to the control (Table 2). Maximum cholesterol $108.19 \pm 2.27 \mathrm{mg} / \mathrm{dL}$ was recorded in the $\mathrm{D}_{1}$ (control) group, while the $\mathrm{D}_{2}(\mathrm{PBC} 1 \%)$ and the $\mathrm{D}_{3}$ (PBC 2\%) groups had a lower mean cholesterol value, i.e. $105.30 \pm 2.43$ and $107.17 \pm 2.80 \mathrm{mg} / \mathrm{dL}$, respectively. During the entire study, the placebo (control) group showed a non-significant increase in cholesterol contents from $107.85 \pm 4.27$ to $112.27 \pm 2.68 \mathrm{mg} / \mathrm{dL}$. On the contrary, PBC $1 \%$ decreased cholesterol contents from $110.16 \pm 3.17$ to $102.75 \pm 3.25 \mathrm{mg} / \mathrm{dL}$. However, higher concentration of powdered black cumin (PBC 2\%) resulted in a varied response as cholesterol decreased in the initial four weeks $(102.38 \pm 2.93 \mathrm{mg} / \mathrm{dL})$, but increased afterwards, and cholesterol contents were recorded $107.04 \pm 4.17 \mathrm{mg} / \mathrm{dL}$ after 56 days of feeding trials.

Table 2: Level of cholesterol $(\mathrm{mg} / \mathrm{dL})$ in normal rats treated with powdered black cumin seeds

\begin{tabular}{lllll}
\hline \multirow{2}{*}{ Diets } & \multicolumn{2}{l}{ Study intervals (Days) } & \multicolumn{2}{l}{ Means } \\
\cline { 2 - 5 } & $\mathbf{0}$ & $\mathbf{2 8}$ & $\mathbf{5 6}$ & \\
\hline $\mathbf{D}_{\mathbf{1}}($ Control) & $107.85 \pm 4.27$ & $104.44 \pm 2.66$ & $112.27 \pm 2.68$ & $108.19 \pm 2.27$ \\
$\mathbf{D}_{\mathbf{2}}(\mathbf{P B C} \mathbf{1 \%})$ & $110.16 \pm 3.17$ & $102.99 \pm 2.86$ & $102.75 \pm 3.25$ & $105.30 \pm 2.43$ \\
$\mathbf{D}_{\mathbf{3}}(\mathbf{P B C} \mathbf{2 \%})$ & $112.08 \pm 5.89$ & $102.38 \pm 2.93$ & $107.04 \pm 4.17$ & $107.17 \pm 2.80$ \\
Means & $110.03 \pm 1.22$ & $103.27 \pm 0.61$ & $107.35 \pm 2.75$ & \\
\hline
\end{tabular}

Means for HDL contents (Table 3) indicated non-significant variations due to the diets. However, it is observed that HDL contents slightly improved in $\mathrm{D}_{2}(\mathrm{PBC} 1 \%)$ and $\mathrm{D}_{3}(\mathrm{PBC} 2 \%)$. Data pertaining to serum triglycerides are presented in Table 4. The results indicated that triglycerides increased in control diets with an overall mean value of $94.51 \pm 2.05 \mathrm{mg} / \mathrm{dL}$. In comparison, $\mathrm{D}_{2}$ (PBC 1\%) containing diets decreased the triglycerides from the baseline values of $87.59 \pm 4.41$ to $80.27 \pm 5.08 \mathrm{mg} / \mathrm{dL}$. However, the supplementation of powdered black cumin seeds at $2 \%$ resulted in a marked increase in triglycerides statistically at par with control diets. 
Table 3: Level of HDL (mg/dL) in normal rats treated with powdered black cumin seeds

\begin{tabular}{lllll}
\hline \multirow{2}{*}{ Diets } & \multicolumn{2}{l}{ Study intervals (Days) } & Means \\
\cline { 2 - 5 } & $\mathbf{0}$ & $\mathbf{2 8}$ & $\mathbf{5 6}$ & \\
\hline D $_{\mathbf{1}}$ (Control) & $44.32 \pm 1.76$ & $44.43 \pm 2.83$ & $44.73 \pm 2.87$ & $44.49 \pm 0.12$ \\
D $_{\mathbf{2}}$ (PBC 1\%) & $45.61 \pm 2.29$ & $48.77 \pm 2.57$ & $51.32 \pm 3.25$ & $48.56 \pm 1.65$ \\
D $_{3}$ (PBC 2\%) & $45.07 \pm 2.37$ & $48.78 \pm 2.19$ & $49.75 \pm 3.15$ & $47.87 \pm 1.43$ \\
Means & $45.00 \pm 0.38$ & $47.33 \pm 1.45$ & $48.60 \pm 1.99$ & \\
\hline
\end{tabular}

Table 4: Level of triglycerides $(\mathrm{mg} / \mathrm{dL})$ in normal rats treated with powdered black cumin seeds

\begin{tabular}{lllll}
\hline \multirow{2}{*}{ Diets } & \multicolumn{2}{l}{ Study intervals (Days) } & Means \\
\cline { 2 - 5 } & $\mathbf{0}$ & $\mathbf{2 8}$ & $\mathbf{5 6}$ & \\
\hline D $_{\mathbf{1}}$ (Control) & $91.55 \pm 3.63$ & $93.53 \pm 5.95$ & $98.45 \pm 6.32$ & $94.51 \pm 2.05 \mathrm{a}$ \\
$\mathbf{D}_{\mathbf{2}}$ (PBC 1\%) & $87.59 \pm 4.41$ & $89.07 \pm 4.69$ & $80.27 \pm 5.08$ & $85.64 \pm 2.72 \mathrm{~b}$ \\
$\mathbf{D}_{\mathbf{3}}$ (PBC 2\%) & $88.57 \pm 4.65$ & $90.26 \pm 4.06 \mathrm{c}$ & $99.97 \pm 6.34$ & $92.93 \pm 3.55 \mathrm{a}$ \\
Means & $89.24 \pm 1.19$ & $90.95 \pm 1.33$ & $92.90 \pm 6.33$ & \\
\hline
\end{tabular}

Means sharing same letters in a column/row do not differ significantly at $\mathrm{P}<0.05$

It is obvious from the means (Table 5) that maximum LDL contents $44.79 \pm 1.90 \mathrm{mg} / \mathrm{dL}$ were recorded in $\mathrm{D}_{1}$ (control) whereas $\mathrm{D}_{2}$ (PBC 1\%) and $\mathrm{D}_{3}$ (PBC 2\%) exhibited lower LDL contents i.e. $39.61 \pm 3.72$ and $40.71 \pm 4.32 \mathrm{mg} / \mathrm{dL}$, respectively. Furthermore, groups of rats fed on $\mathrm{D}_{1}$ showed non-significant increase in LDL from $345.22 \pm 1.79$ to $47.85 \pm 3.07 \mathrm{mg} / \mathrm{dL}$ during the whole study, whilst, diets containing powdered black cumin at $1 \%$ and $2 \%$ decreased LDL level significantly from $47.03 \pm 2.37$ to $35.37 \pm 2.24$ and $49.29 \pm 2.59$ and $37.30 \pm 2.37 \mathrm{mg} / \mathrm{dL}$, respectively.

Table 5: Level of LDL $(\mathrm{mg} / \mathrm{dL})$ in normal rats treated with powdered black cumin seeds

\begin{tabular}{|c|c|c|c|c|}
\hline \multirow{2}{*}{ Diets } & \multicolumn{3}{|c|}{ Study intervals (Days) } & \multirow{2}{*}{ Means } \\
\hline & $\mathbf{0}$ & 28 & 56 & \\
\hline$D_{1}$ (Control) & $45.22 \pm 1.79 b$ & $41.31 \pm 2.63 \mathrm{c}$ & $47.85 \pm 3.07 \mathrm{a}$ & $44.79 \pm 1.90 \mathrm{a}$ \\
\hline$D_{2}(P B C 1 \%)$ & $47.03 \pm 2.37 \mathrm{ab}$ & $36.42 \pm 1.92 \mathrm{~d}$ & $35.37 \pm 2.24 d$ & $39.61 \pm 3.72 b$ \\
\hline $\mathrm{D}_{3}(\mathrm{PBC} 2 \%)$ & $49.29 \pm 2.59 \mathrm{a}$ & $35.54 \pm 1.60 \mathrm{~d}$ & $37.30 \pm 2.37 \mathrm{~d}$ & $40.71 \pm 4.32 b$ \\
\hline Means & $47.18 \pm 1.18 \mathrm{a}$ & $37.76 \pm 1.80 \mathrm{c}$ & $40.18 \pm 3.88 b$ & \\
\hline
\end{tabular}

Means sharing same letters in a column/row do not differ significantly at $\mathrm{P}<0.05$ 


\section{DISCUSSION:}

The Sprague dawley strain of rats is frequently used in efficacy studies to achieve multifarious objectives; the present research investigation was conducted following the protocols already described by Morita et al. [17]. Rats fed on experimental diets containing powdered black cumin at $1 \%$ and $2 \%$ showed some promising results. It is obvious from the present research that diets containing powdered black cumin at $1 \%$ and $2 \%$ improved the lipid profile.

Overall, powdered black cumin at $1 \%$ and $2 \%$ reduced cholesterol level by 6.73 and $4.48 \%$, LDL by 24.79 and $24.32 \%$, respectively, whilst, HDL contents improved nonsignificantly (Figure 1). The improvement in the overall lipid profile can be interpreted due to several reasons. Black cumin is rich in polyunsaturated fatty acids [18] that mainly account for its lipid lowering potential [7]. Some other research interventions also supported the claims of the present research investigation. It produces a favorable effect on serum lipid profile like lowering total cholesterol, LDL, and triglycerides, while elevating the HDL level [19]. Moreover, it was hypothesized that the cholesterol lowering mechanism might be through PPAR $\alpha$ (Peroxisome Proliferator-Activited Receptor) activation [20-21].

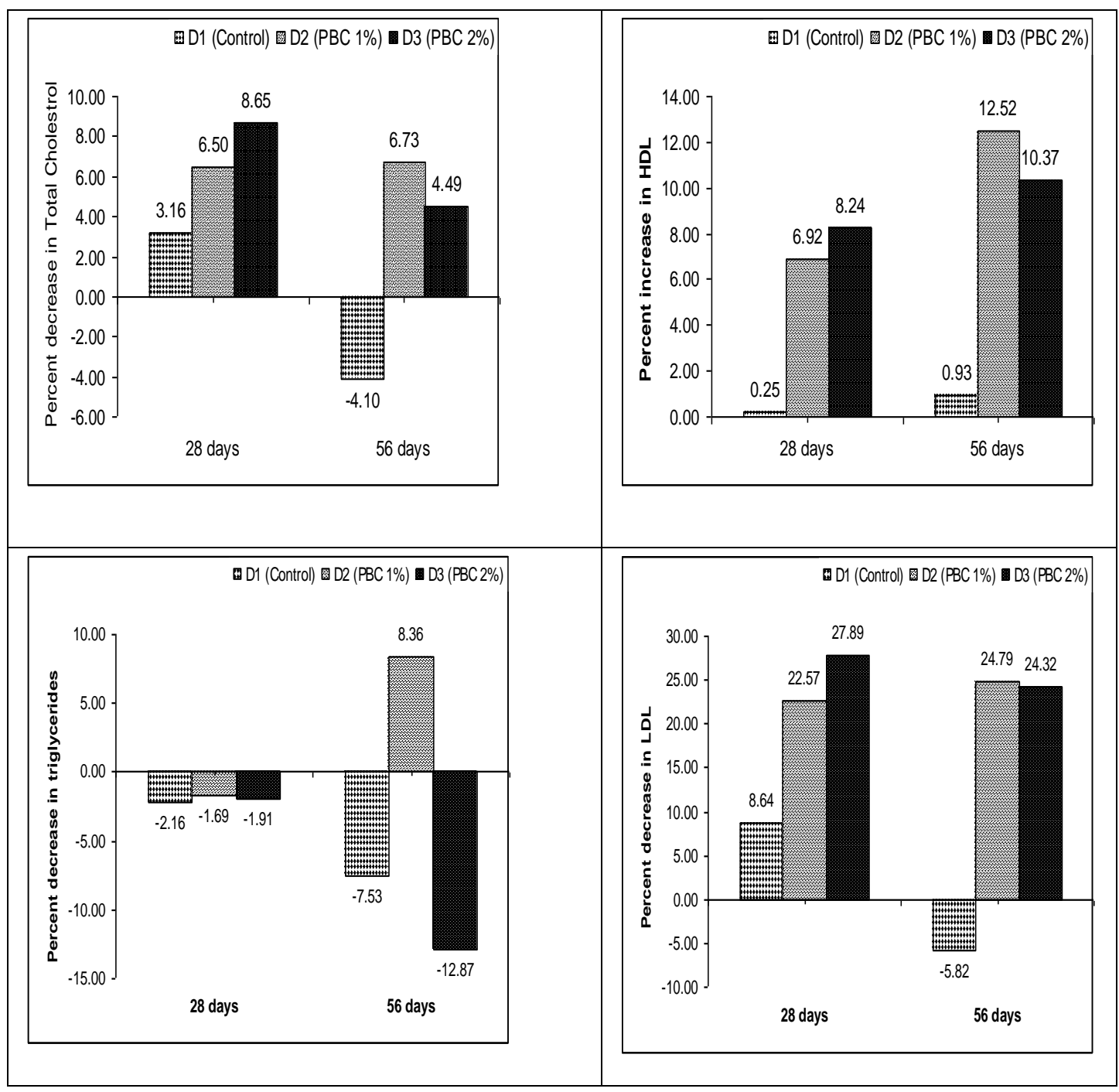

Figure 1: Percent increase/decrease in parameters related to hypercholesterolemia 
The presence of substantial amounts of fat-soluble vitamins, especially tocopherols in black cumin seeds have been highlighted by Ramadan and Mörsel [22] and Al-Saleh et al. [23]. These bioactive compounds are responsible for reducing oxidative modification of LDL, resulting in their clearance from the blood stream. Moreover, the black cumin seeds also contain the appreciable amount of sterols, especially $\beta$-sitosterol that has been bestowed with the ability to inhibit absorption of dietary cholesterol. The active ingredients, i.e. thymoquinone, in few studies were reported to possess hypocholesterolemic potential [7, 24]. The other possible justification of cholesterol reduction is owed to the slight anorexic effect of black cumin, as it reduces the appetite [25].

It is obvious from the present research that diets containing black cumin fixed and essential oils improved the lipid profile, but the effect was more pronounced the in group of rats fed lower doses of powdered black cumin seeds.

\section{CONCLUSION:}

The conclusive approach drawn from this part of the efficacy study is black cumin holds potential to decrease total cholesterol and LDL, however, its dosage needs to be adjusted to bring in the desirable results. Nevertheless, there is need to conduct further trials in similar types of rats, modeling after inducing hypercholesterolemia to validate the findings. Moreover, the different fractions of black cumin seeds should also be tested for their therapeutic potential through animal modeling. The results from such studies would be important for meticulousness of the present findings.

Acknowledgement: The corresponding author is thankful to the Higher Education Commission of Pakistan for providing funding for his $\mathrm{PhD}$ project entitled "Characterization of black cumin fixed and essential oils and exploring their role as functional foods”.

Authors Contributions: M. Tauseef Sultan is the principal investigator and the present research publication is from PhD dissertation; Masood Sadiq Butt is working as Professor and supervised the PhD project; Rabia Shabeer Ahmad is presently working as Assistant Professor in GC University, Faisalabad and contributed to the conceptualization of the research protocol and assisted in writing the manuscript; Rizwana Batool is $\mathrm{PhD}$ scholar and currently working on black cumin proteins and exploring their therapeutic potential. She also helped in finalizing the results and respective statistical analysis; Ambreen $\mathrm{Naz}$ is $\mathrm{PhD}$ scholar and helped in tabulation and final write-up of the manuscripts; Hafiz Ansar Rasul Suleria is a PhD scholar and coordinated in the research and publication

\section{REFERENCES:}

1. Schwager J, Mohajeri MH, Fowler A, Weber P. Challenges in discovering bioactive for the food industry. Curr Opin Biotechnol. (2008), 19: 66-72.

2. Ares G, Giménez A, Gámbaro A. Consumer perceived healthiness and willingness to try functional milk desserts. Influence of ingredient, ingredient name and health claim. Food Qual Prefer. (2009), 20: 50-56. 
3. Espín JC, García-Conesa MT, Tomás-Barberán FA. Nutraceuticals: facts and fiction. Phytochemistry. (2007), 68: 2986-3008.

4. Bech-Larsen T, Scholderer J. Functional foods in Europe: Consumer research, market experiences and regulatory aspects. Trends Food Sci Technol. (2007), 18: 231-234.

5. Sultan MT, Butt MS, Anjum FM, Jamil A, Akhtar S, Nasir M. Nutritional profile of indigenous cultivar of black cumin seeds and antioxidant potential of its fixed and essential oil. Pak J Bot. (2009), 41: 32-40.

6. Butt MS, Sultan MT. Nigella sative: Reduces the risk of various maldies. Crit Rev Food Sci Nutrition. (2010), 50: 654-665

7. Ramadan MF. Nutritional value, functional properties and nutraceuticals applications of black cumin (Nigella sativa L.): an overview. Int J Food Sci Technol. (2007), 42: 12081218.

8. Cheikh-Rouhoua S, Besbesa S, Lognayb G, Bleckerc C, Deroannec C, Attia H. Sterol composition of black cumin (Nigella sativa L.) and Aleppo pine (Pinus halepensis Mill.) seed oils. J Food Comp Anal. (2008), 21: 162-168.

9. Gali-Muhtasib H, Diab-Assaf M, Boltze C, Al-Hmaira J, Hartig R, Roessner A, Schneider-Stock R. Thymoquinone extracted from black seed triggers apoptotic cell death in human colorectal cancer cells via a p53-dependent mechanism. Int J Oncol. (2004), 25: 857-866.

10. Ramadan MF, Mörsel JT. Analysis of glycolipids from black cumin (Nigella sativa L.), coriander (Coriandrum sativum L.) and niger (Guizotia abyssinica Cass.) oilseeds. Food Chem. (2003), 80: 197-204.

11. AACC. (2000). Approved Methods of the American Association of Cereal Chemists, 10th Ed. AACC, St. Paul, MN, USA.

12. Uchida K, Satoh T, Ogura Y, Yamaga N, Yamada K. Effect of partial ileal bypass on cholesterol and bile acid metabolism in rats. Yanago Acta Medica. (2001), 44: 69-77.

13. Stockbridge H, Hardy RI, Glueck CJ. Photometric determination of cholesterol (CHODPAP method). Ecoline® 2S, Merck KGaA, 64271 Darmstadt, Germany. J Lab Clin Med. (1989), 114(2): 142-151.

14. Assmann G. HDL- cholesterol precipitant. Randox Labs. Ltd. Crumlin Co. Antrim, N. Ireland. Internist, (1979), 20: 559.

15. McNamara JR, Cohn JS, Wilson PW, Schaefer EJ. Calculated values for low-density lipoprotein cholesterol in the assessment of lipid abnormalities and coronary disease risk. Clinical Chem. (1990), 36: 36-42.

16. Annoni G, Botasso BM, Ciaci D, Donato MF, Tripodi A. Liquid triglycerides (GPOPAP). Medi. Diagnostic Italy. Lab. J. Res. Lab. Med. (1982). 9: 115.

17. Morita O, Tamaki Y, Kirkpatrick JB, Chengelis CP. Safety assessment of heated diacylglycerol oil: Subchronic toxicity study in rats. Food Chem Toxicol. (2008). 46: 2748-2757.

18. Cheikh-Rouhou S, Besbes S, Hentati B, Blecker C, Deroanne C, Attia H. Nigella sativa L.: Chemical composition and physicochemical characteristics of lipid fraction. Food Chem. (2007), 101: 673-681. 
19. El-Dakhakhny M, Mady NI, Halim MA. Nigella sativa L. oil protects against induced hepatotoxicity and improves serum lipid profile in rats. Arzneimittel-Forschung. (2000), 50: 832-836.

20. Martin G, Duez H, Blanquart C, Berezowski V, Poulain P, Fruchart JC, Najib-Fruchart J, Glineur C, Staels B. Statin-induced inhibition of the Rho-signaling pathway activates PPARalpha and induces HDL apoA-I. J Clin Invest. (2001), 107: 1423-1432.

21. Torra IP, Chinetti G, Duval C, Fruchart JC, Staels B. Peroxisome proliferator-activated receptors: from transcriptional control to clinical practice. Curr Opin Lipidol. (2001), 12: 245-254.

22. Ramadan MF, Mörsel JT. Direct isocratic normalphase assay of fat-soluble vitamins and beta-carotene in oilseeds. Eur Food Res Technol. (2002), 214: 521-527.

23. Al-Saleh I, Billedo AG, El-Doush II. Levels of selenium, DL-a-tocopherol, DL-gtocopherol, all-trans-retinol, thymoquinone and thymol in different brands of Nigella sativa seeds. J Food Comp Anal. (2006), 19: 167-175.

24. Badary OA, Abdel-Naim AB, Abdel-Wahab MH, Hamada FM. The influence of thymoquinone on doxorubicin-induced hyperlipidemic nephropathy in rats. Toxicology. (2000), 143: 219-226.

25. Sultan MT, Butt MS, Anjum FM. Safety assessment of black cumin fixed and essential oil in normal Sprague dawley rats: Serological and hematological indices. Food Chem Toxicol. (2009), 47: 2768-2775. 